Resumen por los autores, Albert Kuntz y O. V. Batson, Saint Louis University.

Observaciones experimentales sobre la histogénesis de los troncos del simpático en el pollo.

Embriones de pollo de cuarenta y ocho horas de incubación fueron sometidos a una operación que consistió en la destrucción de las crestas neurales y porción dorsal del tubo neural en una porción limitada del tronco. Los embriones que sobrevivieron a la operación y continuaron desarrollándose fueron preparados al final del cuarto o quinto dia y fijados para estudio.

En algunos de estos embriones faltan los ganglios espinales y las raices nerviosas dorsales, bien sea en ambos lados del cuerpo o en un solo lado, en una serie de segmentos sucesivos en los cuales existen las raices ventrales.

Los primordia de los ganglios de los troncos del simpático existen en todos estos segmentos son excepción de unos pocos en los cuales el resto de tubo neural es muy pequeño y las raices nerviosas ventrales están poco desarrolladas. Indudablemente, estos primordia de los ganglios del simpático se originaron a expensas de células de origen medular que avanzaron periféricamente a lo largo de los caminos seguidos por las raices ventrales de los nervious espinales. 


\title{
EXPERIMENTAL OBSERVATIONS ON THE HISTO- GENESIS OF THE SYMPATHETIC TRUNKS IN THE CHICK
}

\author{
ALBERT KUNTZ AND O. V. BATSON \\ Department of Anatomy, St. Louis University School of Medicine \\ THREE FIGURES \\ INTRODUCTION
}

According to the older teaching the primordia of the sympathetic trunks arise from cells which become displaced from the spinal ganglia. Some of the more recent investigators who have studied the histogenesis of the sympathetic nervous system have presented evidence which indicates both that cells which become displaced from the spinal ganglia and cells which migrate from the ventral portion of the neural tube take part in the development of the sympathetic trunks; others still maintain that the ganglia of the sympathetic trunks arise exclusively from cells which advance peripherally from the spinal ganglia. The literature bearing on this problem was reviewed recently by one of the present writers (Kuntz '20) ${ }^{1}$ and will not be considered further in this paper.

The senior author has for ten years advocated the theory that cells of medullary origin play an important part in the development of the sympathetic nervous system; nevertheless, he has long recognized the limitations of direct observation on normal embryonic material as a method of obtaining conclusive evidence on this point. The cells of ganglionic and medullary origin which become displaced from the cerebrospinal nervous system

1 The development of the sympathetic nervous system in man. Jour. Comp. Neur., vol. 32, pp. 173-229. 
advance peripherally along the paths of the dorsal and ventral roots of the spinal nerves respectively. They are identical in appearance; consequently, in embryos of the higher vertebrates, those from the one source cannot be distinguished from those from the other source after they have advanced beyond the junction of the dorsal and ventral nerve-roots. Therefore, the fact that cells deviate from the paths of the spinal nerves and enter the primordia of the sympathetic trunks does not prove conclusively that these primordia comprise both cells of ganglionic and medullary origin. The chief contentions of those who maintain that only cells which advance peripherally from the spinal ganglia enter the primordia of the sympathetic trunks are: 1) that migration of cells from the ventral part of the neural tube, if it occur at all in embryos of the higher vertebrates, is not abundant, and 2) that such cells as may advance from the neural tube along the fibers of the ventral roots of the spinal nerves become incorporated in the neurilemma.

In view of the present status of this problem it has seemed desirable to obtain crucial experimental evidence regarding the contribution of cells from the neural tube to the primordia of the sympathetic trunks. If the neural crests and the dorsal portion of the neural tube could be eliminated before the spinal ganglia have become differentiated and the embryo could continue to develop without spinal ganglia and dorsal nerve-roots, the remaining portion of the neural tube would be the only source from which cells of nervous origin could migrate along the paths of the spinal nerves. If in such embryos the primordia of the sympathetic trunks should arise, they would of necessity arise from cells which migrate from the neural tube along the paths of the ventral roots of the spinal nerves.

The observations set forth in this paper are based on embryos of the chick which were early subjected to an operative procedure by which the dorsal portion of the cerebrospinal nervous system was destroyed throughout a limited portion of the trunk region. This material affords conclusive evidence that cells of medullary origin which advance peripherally along the ventral roots of the spinal nerves enter the primordia of the sympathetic trunks. 


\section{TECHNIQUE}

The operative technique employed does not differ essentially from that which was described recently by Clark ('20). ${ }^{2}$ The destruction of tissue was accomplished by electrolysis. The negative electrode, which was placed on the region to be destroyed, consisted of a very fine metallic filament.

The embryos were subjected to operation at the close of the second day (48 hours) of incubation. At this time the spinal ganglia are not yet differentiated, and in the posterior portion of the trunk the neural tube is not yet closed. An, attempt was made to destroy just enough tissue along the dorsal aspect of the embryo to insure the complete elimination of the neural crest material, but to leave the ventral half of the neural tube intact. It is quite impossible at the time of operation to determine just how much tissue is destroyed. In some instances the desired result was obtained; in others either the destruction of tissue was not sufficiently extensive to insure the complete elimination of the spinal ganglia, or it was so extensive that the neural tube was almost or completely destroyed. Two of the embryos which survived the operation and continued to develop were killed at the close of the fourth day (96 hours); the others at the close of the fifth day (120 hours) of incubation.

\section{DESCRIPTION OF MATERIAL}

A total of seven embryos in which the operation was effective survived until they were killed to be prepared for study. In all of these the portion of the trunk involved showed some distortion, otherwise the embryos were quite normal in appearance. Sections of these embryos indicate a marked degree of regeneration of tissue in the effort to repair the injury caused by the operation. Throughout the greater part of the region involved in all of the embryos the neural canal is closed and the mesodermal and ectodermal layers are completed dorsally. However, wherever the neural crests and the dorsal portion of the neural tube

\footnotetext{
2 Technique of operating on chisk embryos. Science, N. S., vol. 51, pp.
} 371-373. 
were successfully destroyed these parts are not restored. Most commonly the remnant of the neural tube as repaired contains a single small neural canal which is lined by an ependymal layer. At certain points an attempt at duplication occurred in which two small neural canals were formed. At some points the operative procedure apparently caused some displacement of masses of nervous tissue which continued to live. At such points may be observed the rudiments of three or four distorted neural canals.

In one of the embryos which were killed at the close of the fourth day of incubation development was materially retarded; in the other only the posterior portion of the trunk was involved in the operation. In one of the other embryos the destruction of tissue was not sufficiently extensive to insure the complete absence of spinal ganglia except in a few segments on one side only. These three embryos were discarded for the purposes of this study. The following observations are based on preparations of the four remaining embryos all of which were killed at the close of the fifth day (120 hours) of incubation.

Number 1. In this embryo the operation involved the nervous system throughout the lower thoracic, lumbar and sacral regions. The destruction of tissue occurred asymmetrically. In the thoracic region spinal ganglia and dorsal nerve-roots are absent unilaterally in four successive segments. In the next two segments the spinal ganglia are „represented by small aggregates of ganglion cells and the dorsal nerve-roots by relatively few fibers. Continuing caudad spinal ganglia and dorsal nerveroots are completely absent on the same side in several successive segments. Spinal ganglia and dorsal nerve-roots are present on the opposite side in all of these segments. In some segments they are approximately of normal size; in others they are materially reduced. The primordia of ganglia of the sympathetic trunks are present bilaterally in all of these segments. Obviously, the primordia of the sympathetic ganglia which are associated with those spinal nerves which are represented by the ventral roots only arose from cells which advanced from the neural tube along the paths of these ventral nerve-roots. Farther posteriorly the destruction of nervous tissue was more extensive, and 
the sections indicate considerable distortion. In a few segments in this region in which small ventral nerve-roots are present the primordia of the sympathetic trunks are wanting.

The conditions which obtain in one of the thoracic segments on the side on which the spinal ganglion and dorsal nerve-root are absent are illustrated in figure 1. In this segment the ventral nerve-root is relatively large. There is also evidence of abundant migration of cells of medullary origin along. its fibers. That such migration was still in progress at the close of the fifth day of incubation is indicated by the fact that continuous lines of cells may be traced from the motor nidulus into the ventral nerveroot and that cells of medullary origin are abundant in the proximal portion of the nerve. Such cells are present also along the fibrous communicating ramus which connects the primordium of the sympathetic trunk with the spinal nerve. This primordium is approximately as large as the primordium of the sympathetic trunk on the opposite side in this segment where both spinal ganglion and dorsal nerve-root are present.

In order to show approximately what portion of the neural tube is wanting in this segment, a camera lucida outline of the entire cross section of its remnant is superimposed (figure 1, A) on a camera lucida outline of the same magnification of a cross section of the neural tube a few segments farther cephalad where it was not affected by the operation.

Number 2. In this embryo the operation involved the nervous system in the lumbar and sacral regions. In the anterior portion of the region involved the neural tube is almost completely absent. In a few segments only a few small masses of nervous tissue remain along the dorsal aspect of the notochord. From these masses fibers which, doubtless, represent the ventral roots of the spinal nerves grow out on one or both sides in each segment. Continuing caudad a larger portion: of the central nervous system is left intact. Transverse sections show a small distorted neural tube which contains a small but complete neural canal. In a few segments small groups of nervous elements lie outside the neural tube. These may or may not be cells of neural crest origin. Ventral nerve-roots as well as fibers which emerge 
from the cell-masses lying outside the neural tube are present in these segments. In the posterior portion of the region involved in the operation the destruction of tissue was less extensive. In these segments the ventral portion of the neural tube appears nearly normal. The dorsoventral diameter of the neural tube is materially reduced. Two small neural canals each of which is surrounded by an ependymal layer are present. One of these canals occupies the position of the ventral portion of the normal neural canal; the other lies in an asymmetrical position in the dorsal portion of the remnant of the neural tube (fig. 2). In several segments at this level spinal ganglia and dorsal nerveroots are absent unilaterally. On the opposite side nerve cells lying outside the neural tube but not apparently involved in the ventral nerve-roots are present in all of these segments. These cell-aggregates may be of neural crest origin, but they do not constitute definitive spinal ganglia. Cell-aggregates which constitute the primordia of the ganglia of the sympathetic trunks are present in every segment in which there is a well defined ventral nerve-root throughout the entire region affected by the operation; consequently, the primordia of the sympathetic ganglia in those segments in which the spinal ganglia and dorsal nerve-roots are wanting must have arisen from cells which advanced from the neural tube along the paths of the ventral nerve-roots.

Figure 2 is taken from a section from one of the segments in which the remnant of the neural tube contains two neural canals and from which the spinal ganglia and dorsal nerve-root are absent. In this segment a sympathetic primordium of considerable size is connected with the ventral nerve-root by means of a fibro-cellular communicating ramus. The presence of numerous cells of nervous origin along the spinal nerve and the communicating ramus suggests that migration along this path has not yet ceased. The primordia of the prevertebral plexuses are already present. A few nerve-fibers emerge from the dorsal portion of the remnant of the neural tube in this segment; however, they do not join the ventral nerve-root, but grow into the differentiating myotome. The relation of these fibers to the myotome suggests that they are not sensory, but motor fibers; consequently, they do not represent the dorsal nerve-root. 
Number 3. In this embryo the operation involved the nervous system in the lower thoracic and lumbar regions. The neural tube is reduced to less than one third its normal size in not less than ten successive segments. Spinal ganglia and dorsal nerve-
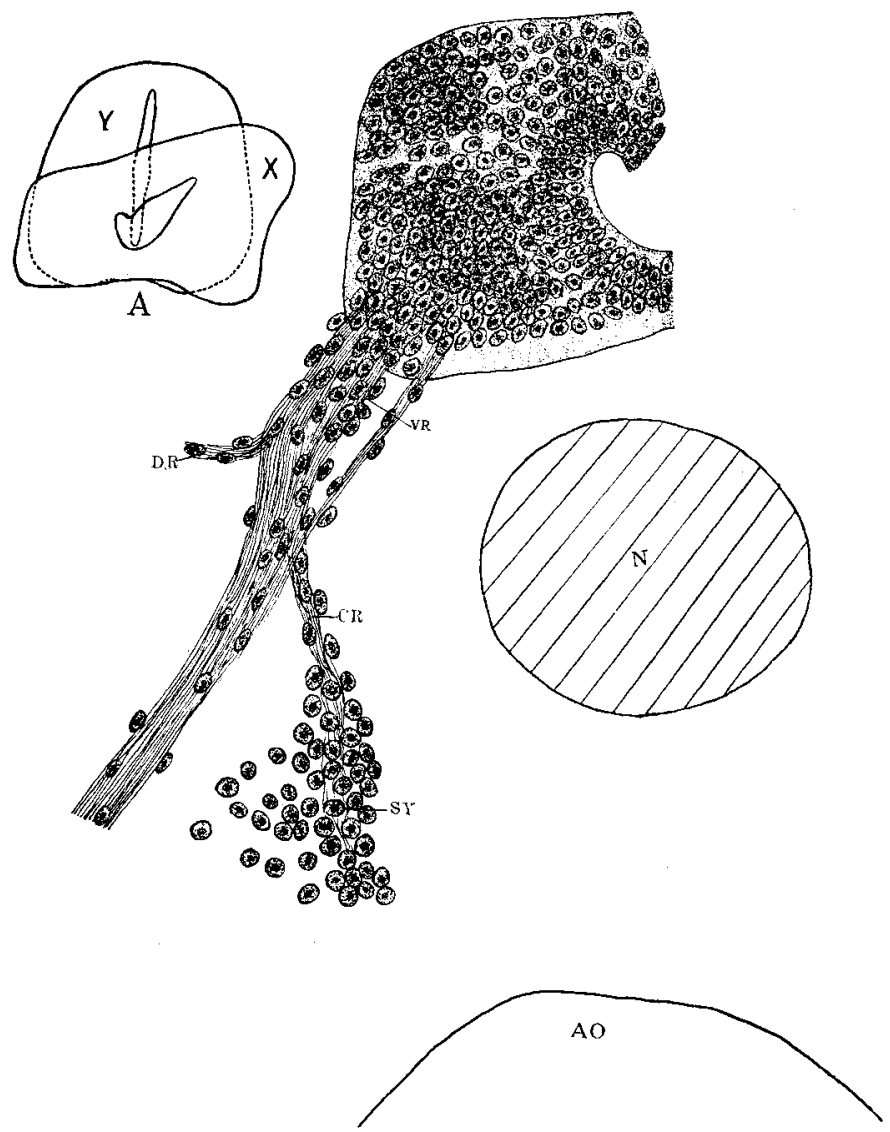

Fig. Transverse section from a segment of embryo number 1 , in which spinal ganglion and dorsal nerve-root are absent. $\times 165 . A O$, aorta; $C R$, communicating ramus; $D R$, dorsal ramus; $N$, notochord; $S Y$, sympathetic trunk; $V R$, ventral root of spinal nerve.

A. Camera lucida outline of a cross section of the remnant of the neural tube $(X)$ in the segment from which figure 1 is taken superimposed on a camera lucida outline of the same magnification of a cross section of the neural tube $(Y)$ a few segments farther cephalad where it was not affected by the operation. 
roots are entirely absent in at least six successive segments. Nevertheless, sympathtic primordia related to the ventral roots of the spinal nerves are present bilaterally in all of these segments.

Figure 3 is reconstructed from several sections from one of the segments in this series. In order to show approximately what portion of the neural tube is wanting at this level, a camera lucida outline of the cross section of its remnant is superimposed (fig. 3, A) on a camera lucida outline of the same magnification of a cross section of the neural tube taken several segments farther cephalad where it was not affected by the operation. As indicated in figure 3, a small aggregate of cells of nervous origin which is not incorporated in the wall of the neural tube lies along one of its dorsolateral aspects in the segment from which this figure was taken. Apparently a few cells migrate from this cellaggregate along the ventral nerve-root. In view of the extensive destruction of the nervous tissue which occurred at this level it is quite improbable that these are cells of neural crest origin. They probably represent cells of medullary origin which became somewhat displaced by the operative procedure and did not again become incorporated in the wall of the neural tube. No cells similarly located were observed on the opposite side in the same segment nor on either side in any of the other segments in this series. As indicated in the figure, the sympathetic primordia in this instance are relatively small and somewhat asymmetrical.

NUMBER 4. In this embryo the operation involved the nervous system from the level of the anterior to the level of the posterior limb-buds. The destruction of tissue was somewhat more extensive in this case than in any of the others. In several segments in the anterior portion of the region involved the central nervous system is represented by a very slender column of nervous tissue in which there is no neural canal. Advancing caudad the remnant of the neural tube becomes somewhat larger and contains a small neural canal. Farther posteriorly it again becomes smaller until at a level just anterior to the posterior limb-buds the central nervous system is entirely absent. Spinal ganglia and dorsal nerve-roots are absent bilaterally in every 
segment from the level of the anterior to the level of the posterior limb-buds. Ventral nerve-roots are present bilaterally or uni-

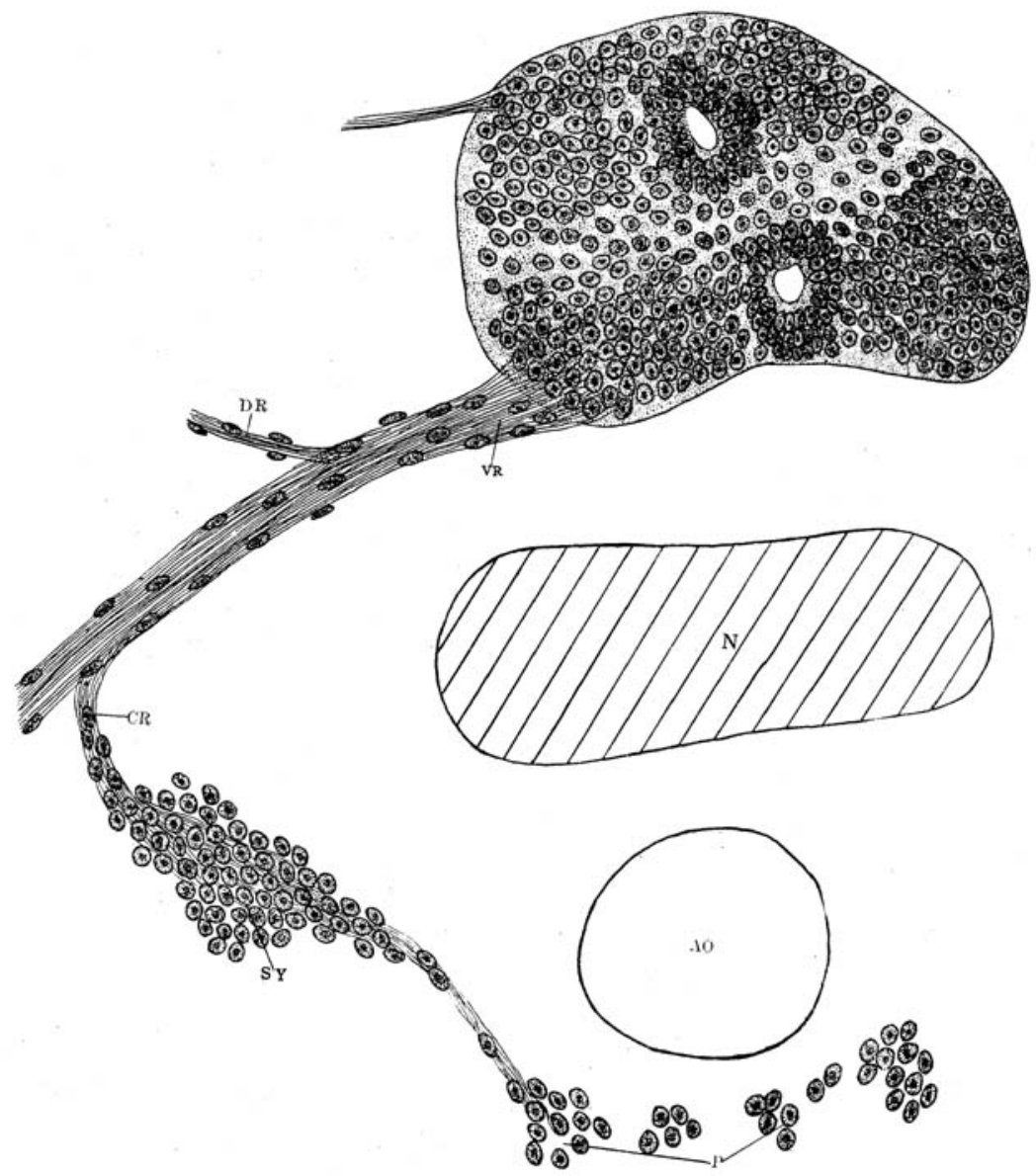

Fig. 2 Transverse section from a segment of embryo number 2, in which two neural canals are present and spinal ganglion and dorsal nerve-root are absent. $\times 165$. $A O$, aorta; $C R$, communicating ramus; $D R$, dorsal ramus; $N$, notochord; $P$, prevertebral plexus; $S Y$, sympathetic trunk; $V R$, ventral root of spinal nerve.

laterally in every segment in which there remains an appreciable remnant of the neural tube. Some of these ventral nerve-roots comprise relatively few fibers; others are larger, but none are of 
normal size. In the thoracic portion of the region involved, small sympathetic primordia occur associated with the ventral nerveroots in several segments. In those segments in which the ventral nerve-roots are very small or absent sympathetic primordia are absent.

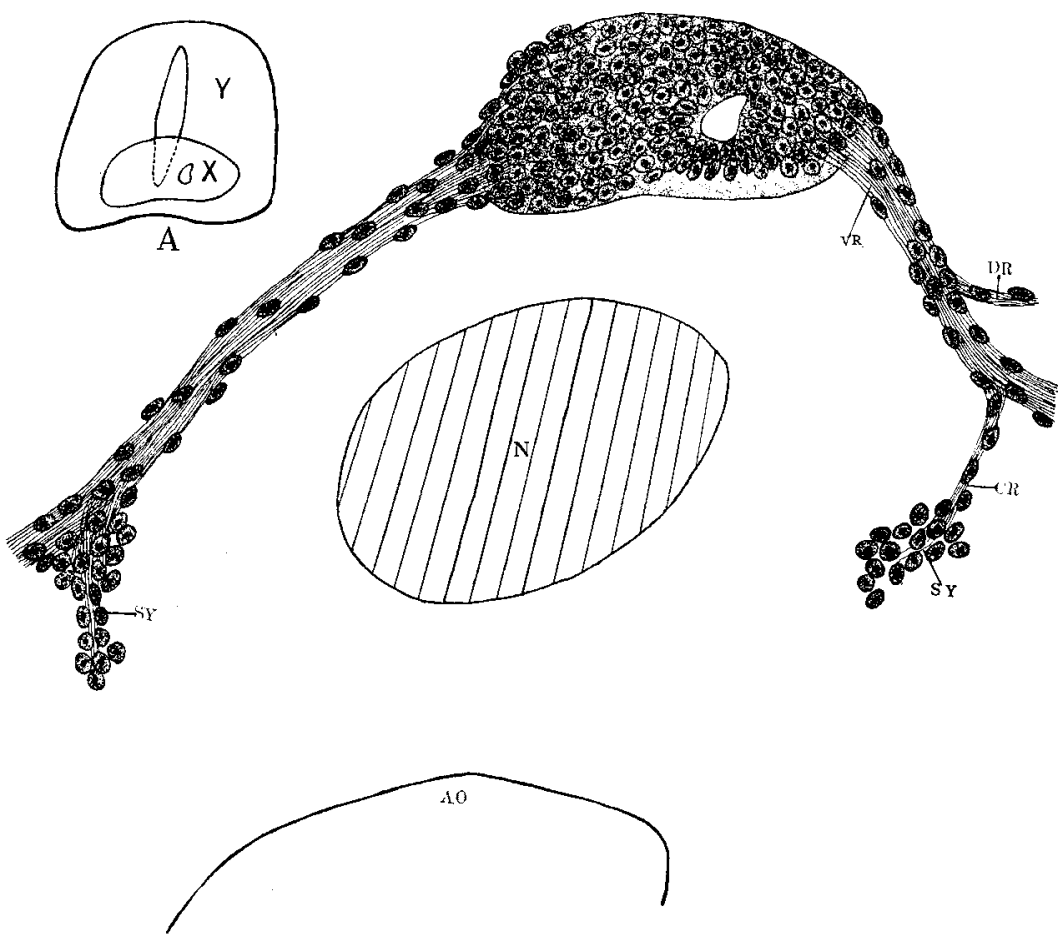

Fig. 3 Transverse section from a segment of embryo number 3 , in which spinal ganglia and dorsal nerve-roots are absent. $\times 165 . A O$, aorta; $C R$, communicating ramus; $D R$, dorsal ramus; $N$, notochord; $S Y$, sympathetic trunk; $V R$, ventral root of spinal nerve.

A. Camera lucida outline of a cross section of the remnant of the neural tube $(X)$ in the segment from which figure 3 is taken superimposed on a camera lucida outline of the same magnification of a cross section of the neural tube $(Y)$ a few segments farther cephalad where it was not affected by the operation. 


\section{CONCLUSIONS}

The observations recorded in the preceding pages demonstrate clearly that the primordia. of the ganglia of the sympathetic trunks may arise in the absence of spinal ganglia and dorsal nerve-roots; consequently, cells of medullary origin which advance peripherally along the paths of the ventral roots of the spinal nerves enter these primordia. The spinal ganglia are not excluded as a source from which cells may enter the primordia of the sympathetic trunks under normal conditions; however, these primordia may arise from cells derived from the neural tube only, at least when cells which have their origin in the spinal ganglia (or neural crest) are excluded.

As observed above, the primordia of the ganglia of the sympathetic trunks may be approximately of normal size in segments in which the spinal ganglia and dorsal nerve-roots are absent, but the remnant of the neural tube is relatively large. On the other hand, these primordia are small or entirely absent in segments in which the remnant of the neural tube is small and represents only the most ventral portion of the central nervous system, even though ventral nerve-roots are present. These facts suggest that the cells which normally give rise to the ganglia of the sympathetic trunks are derived largely from those portions of the walls of the neural tube which give rise to the lateral cell-columns. Theoretical considerations also favor this interpretation; however, we do not feel that the evidence at hand warrants a definite conclusion on this point. 